\section{Paralisia bilateral do hipoglosso na evolução de otite externa necrotizante}

\author{
Adriano Santana Fonseca ${ }^{1}$, Nilvano Alves de Andrade ${ }^{2,}$ \\ Miguel Leal Andrade Neto ${ }^{3}$, Vyrna Medeiros de Moura \\ Santos $^{4}$
}

\section{Bilateral hipoglossal nerve palsy in necrotizing otitis externa.}

\author{
Palavras-chave: otite externa, otite necrotizante, paralisia do \\ hipoglosso. \\ Keywords: otitis externa, necrotizing otitis, nerve palsy.
}

\section{INTRODUÇÃO}

A otite externa necrotizante é uma infecção potencialmente letal que começa no conduto auditivo externo e pode estender-se à base do crânio. Ocorre em diabéticos idosos e está associada à elevada morbi-mortalidade. ${ }^{1}$ O agente causal principal é a Pseudomonas aeruginosa, em 96 a $98 \%$ dos $\operatorname{casos}^{2}$.

A infeccão se estende da juncão ósteo-cartilaginosa ao osso temporal através das fissuras de Santorini. A infecção pode progredir à base do crânio e afetar os nervos facial, glossofaríngeo, vago e acessório. Eventualmente afeta o nervo hipoglosso, abducente e trigêmeo.

Sintomas como otalgia, cefaléia, hipoacusia, otorréia, em pacientes diabéticos ou imunossuprimidos, são significativos. A investigação laboratorial revela elevação da VHS, com leucograma normal ou discretamente elevado. A clínica mostra sinais de ulceração em assoalho de CAE. A TC demonstra destruição óssea e a RMN objetiva a localização e extensão da infecção, da invasão intracraniana e comprometimento dos pares cranianos. A cintilografia com tecnécio e gálio tem sido utilizada para avaliação do critério de cura. A cintilografia com tecnécio é útil para diagnóstico de osteíte, sendo positiva em casos de osteomielite aguda ou crônica, ou trauma. Apresenta uma baixa especificidade e pode permanecer positiva por um ano ${ }^{2}$. Já a cintilografia com gálio-67 é utilizada para seguimento e aferição da resposta terapêutica, uma vez que o gálio tem grande afinidade por leucócitos e proteínas da fase aguda. ${ }^{2}$

Para o tratamento adequado é necessária cultura, porém não se espera o resultado para o tratamento inicial. Dois antibióticos empíricos são utilizados: aminoglicosídeo, associado à ciprofloxacina ou a ceftazidima. O cefepime, cefoperazona, imipenem e aztreonam podem ser alternativas. A duração do tratamento é de 4-6 semanas.1 A diminuição ou cessação da otalgia é um importante parâmetro de controle. A maioria dos pacientes pode ser tratada clinicamente e a cirurgia tem indicações controversas, entre elas: dor progressiva, neuropatia craniana e persistência de granulação no CAE. A mastoidectomia pode ser empregada, porém não impede extensão para a base do crânio, em alguns casos. ${ }^{3}$

\section{RELATO DO CASO}

$\mathrm{AAB}, 71$ anos, masculino, procedente de Salvador, portador de hipertensão e Diabetes, se apresentou em agosto de 2004 com história de 2 meses de otalgia à direita. Havia feito uso de antibióticos (cefalexina, moxifloxacino e gatifloxacino) sem melhora do quadro, passando a evoluir com dor lancinante. Ao exame apresentava sinais de otite média com espessamento do CAE, sem ulceração. A TC (junho de 2004) evidenciava obliteração da orelha média e mastóide à direita. A avaliação audiométrica revelava hipoacusia mista.

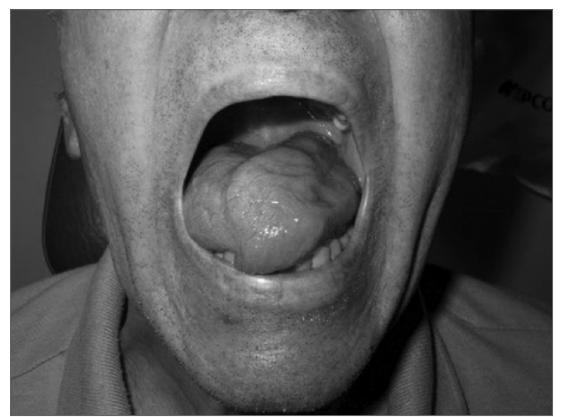

Figura 1. Tentativa de protruir a língua com a infecção acometendo espaço retrofaríngeo.

Com a hipótese de mastoidite o paciente foi tratado com ciprofloxacino por 21 dias e evoluiu com remissão dos sintomas.

Em outubro de 2004 retornou com recidiva da otalgia e nova TC evidenciou ruptura da cortical externa da mastóide.

O paciente foi submetido à mastoidectomia com estudo anatômico revelando inflamação crônica inespecífica, e cultura positiva para Pseudomonas. Iniciado tratamento com ciprofloxacino $1500 \mathrm{mg} / \mathrm{dia}$, 6 semanas.

Compensação do diabetes, controle da dor, e epitelização da cavidade radical foi o resultado do tratamento. Por isso não solicitamos cintilografia para controle inicial.

Após 4 meses retorna referindo cefaléia e paralisia da língua (Figura 1). Internado, realizou nova TC revelando captação de contraste do ápice petroso até a retrofaringe, e obliteração da cavidade radical. A cintilografia com tecnécio foi inconclusiva.
Biópsia e cultura da mucosa da cavidade mastóidea direita e da retrofaringe via endoscópica nasal revelou processo inflamatório inespecífico na cultura Pseudomonas.

$\mathrm{O}$ paciente permaneceu internado com cefepime e amicacina 8 semanas. Obteve alta, assintomático, com TC sem captação anormal de contraste e com diabetes controlado.

Após 10 semanas voltou a apresentar cefaléia, piora da disfagia e otorréia contralatera com hipoacusia. Nova TC revelou mastoidite bilateral e massa retrofaríngea se estendendo até orofaringe.

Hemoculturas e cultura da secreção na orelha esquerda revelaram Pseudomonas e biópsia da musculatura da orofaringe, processo inflamatório crônico inespecífico. Paciente permaneceu internado por 1 semana e obteve alta com cateter central para uso ambulatorial de $4 \mathrm{~g}$ de cefepime dia, 6 meses. Paciente realizou tratamento e está em acompanhamento há 10 meses, assintomático com sinais de reinervação da língua.

\section{DISCUSSÃO}

A otite externa necrotizante, descrita pela primeira vez por Chandler, em 1968, é uma infecção agressiva da orelha externa que acomete a pele, cartilagem e o osso temporal.

A antibioticoterapia venosa é o tratamento, desde que não haja osteomielite, situação que indica cirúrgia. ${ }^{1-3}$

A evolução da OEN para musculatura cervical e para mastóide contralateral é rara. ${ }^{3}$ Evolução benigna após a progressão para osteomielite de base de crânio também constitui uma raridade estatística, visto que a taxa de mortalidade é de $60-80 \%$ nestes casos. ${ }^{3}$

\section{REFERÊNCIAS BIBLIOGRÁFICAS}

1.Benecke JA Jr. Management of osteomyelitis of the skull base. Laryngoscope 1989;99(12):1220-23.

2.Boringa JB, Hoekstra OS, Roos JW, Bertelsmann FW. Multiple cranial nerve palsy after otitis externa: a case report. Clin Neurol Neurosurg 1995;97:332-5.

3.Rubin J, Yu VL. Malignant external otitis: insights into pathogenesis, clinical manifestations and therapy. Am J Med 1998;85:391-8.

\footnotetext{
Especialista em Otorrinolaringologia e Cirurgia de Cabeça e Pescoço pelo HC/UNICAMP., Professor assistente de Cirurgia de Cabeça e Pescoço da Santa Casa de Salvador - Hospital Santa Izabel. Chefe da Clínica de Otorrino do Hospital Naval de Salvador. Disfagologista e Cirurgião de Cabeça e Pescoço do NOEV/Hospital da Bahia.

${ }^{2}$ Mestre em Cirurgia pela UFBA e Doutor em Otorrinolaringologia pela USP., Coordenador da Residência de Otorrinolaringologia do Hospital Santa Izabel e chefe do Serviço de Otorrinolaringologia e Cirurgia de Cabeça e Pescoço do Hospital Santa Izabel, Santa Casa de Misericórdia da Bahia.

Médico-Residente de Otorrinolaringologia do Hospital Santa Izabel, Santa Casa de Misericórdia da Bahia., Médico-Residente de Otorrinolaringologia do Hospital Santa Izabel, Santa Casa de Misericórdia da Bahia.

[4] Médica-Residente de Otorrinolaringologia do Hospital Santa Izabel, Santa Casa de Misericórdia da Bahia.

Hospital Santa Izabel, Santa Casa de Misericórdia da Bahia.

Endereço para correspondência: Unidade de Otorrinolaringologia - Hospital Santa Izabel Praça Almeida Couto 500 Nazaré Salvador BA $40050-410$. Este artigo foi submetido no SGP (Sistema de Gestão de Publicações) da RBORL em 17 de dezembro de 2005. cod. 1652 Artigo aceito em 20 de julho de 2006.
} 